\title{
RESEARCH OF PSYCHOLOGICAL READINESS OF DOCTORS TO ADAPTIVE TRAINING
}

DOI: $10.36740 /$ WLek202103202

\author{
Svitlana P. Koshova, Zoriana V. Hbur, Andriy V. Kolomoyets \\ SHUPYK NATIONAL MEDICAL ACADEMY OF POSTGRADUATE EDUCATION, KYIV, UKRAINE
}

\begin{abstract}
The aim: To empirically investigate the psychological readiness of physicians for adaptive learning during the acquisition of professional competences in the system of postgraduate medical education.

Materials and methods: We surveyed a sample of 148 physicians who began studying the discipline of Psychology of Conflict, which was specially developed by us on the principles of adaptive learning. There were three occupational groups among doctors: surgeons $(n=47)$, therapists $(n=53)$ and pediatricians $(n=48)$.

In the work a range of methods are used: content analysis, biblio-semantic, systematic approach, analysis of products of activity, psycho-diagnostic methods.

Results: When characterizing the identified and calculated integral indicators, the most pronounced for the entire study sample is the desire for dominance (85\%), adaptation and emotional comfort at $75 \%$. The lowest percentage of self-perception - 65\%, slightly higher internality (68\%). Acceptance of others at $78 \%$.

In general, the dominant factor of the 148 physicians was service motived, indicating that this group is truly focused on the benefit of their patients and others. Our researchers perceive their work as a service, as a means of being useful to people, society and humanity as a whole. This is an indicator of high readiness for adaptive learning in the postgraduate medical education system.

The results of the method of "Self-regulation style of behavior" by the doctors of the three medical specialties studied by us testify to their readiness for active inclusion in the system of adaptive training in postgraduate medical education.

Conclusions: Based on the results of our empirical study, we are able state that the doctors who participated in the study are ready for adaptive training in the system of postgraduate medical education. The results of our research can be basis for drafting recommendations for adaptive education, which can be grounded on a competent approach.
\end{abstract}

KEY WORDS: Adaptation Learning, Education, Readiness, Motive, Self-regulation

Wiad Lek. 2021;74(3 p.II):572-577

\section{INTRODUCTION}

While educating modern physicians, medical education professionals face challenges that are fundamentally different from those of previous generations. Over the last few decades, changes in health care and the development of medicine have led to increased demands for educational material, leaving less time for teaching. Changes in care settings, from intensive care units to facilities for the support of people with chronic disorders, require appropriate adjustment in the educational field. Finding time to study such "new" areas as genomics, palliative care, geriatrics, or adjunct medicine can be a difficult task, especially when medical school curricula are already overloaded with "traditional" subjects.

Conventional teaching, centered on the teacher figure, has given way to a student-centered model that gives students control over their learning.

The prolonged progress in the psychological and pedagogical sciences opens the horizons of potential for improving medical education. This progress is relevant to almost all fields of medicine and is directly linked to the potential maximization of the benefits of modeling and implementing the latest technologies.
A key innovation in the training of health care professionals is modeling and other aspects of health education and is reflected in adaptive learning.

Adaptive learning technologies can optimize learning for each individual, integrate objective assessment throughout the learning process, and implement effective learning material acquisition criteria.

Until recently, it was considered that professionalism, as a matter of fundamental importance to medicine and society, should be absorbed directly throughout the period of medical education. As a result, most teachers in the medical disciplines were actively involved in the creation and implementation of structured programs (including postgraduate programs) training and assessment of professionalism, combined with the programs of professional retraining and development of the teaching corps itself.

Teaching and training of professionalism was positioned as one of the priority goals in higher educational establishments of medical education. Based on the experience and development of our understanding of the formation of a professional in the medical field, we believe that such an educational goal is too narrow and should be broadened and reformulated based on the notion of professional identity formation in the process of adaptive physician training. 
Table I. Arithmetic mean values by the method of diagnostics of social and psychological adaptation of Rogers - Diamond

\begin{tabular}{|c|c|c|c|c|c|}
\hline № & Indicators & $\begin{array}{l}\text { Surgeons } \\
(n=47)\end{array}$ & $\begin{array}{l}\text { Therapists } \\
\qquad(n=53)\end{array}$ & $\begin{array}{l}\text { Pediatricians } \\
\quad(n=48)\end{array}$ & $\begin{array}{l}\text { Overall } \\
(n=148)\end{array}$ \\
\hline 1. & Adaptability & 108 & 121 & 115 & 115 \\
\hline 2. & Disadaptability & 45 & 34 & 39 & 39 \\
\hline 3. & Falsehood & 3 & 4 & 2 & 3 \\
\hline 4. & Self-acceptance & 43 & 28 & 37 & 36 \\
\hline 5. & Failure to accept oneself & 9 & 15 & 12 & 12 \\
\hline 6. & Acceptance of others & 14 & 20 & 25 & 20 \\
\hline 7. & Non-acceptance of others & 26 & 15 & 7 & 16 \\
\hline 8. & Emotional comfort & 17 & 29 & 23 & 23 \\
\hline 9. & Emotional discomfort & 22 & 15 & 18 & 18 \\
\hline 10. & Internal control & 48 & 39 & 37 & 41 \\
\hline 11. & External control & 16 & 20 & 22 & 19 \\
\hline 12. & Domination & 14 & 10 & 8 & 11 \\
\hline 13. & Conquest & 9 & 12 & 15 & 12 \\
\hline 14. & Escapism & 8 & 16 & 11 & 12 \\
\hline
\end{tabular}

\section{THE AIM}

To empirically investigate the psychological readiness of physicians for adaptive learning during the acquisition of professional competences in the system of postgraduate medical education.

\section{MATERIALS AND METHODS}

We surveyed a sample of 148 physicians who began studying the discipline of Psychology of Conflict, which was specially developed by us on the principles of adaptive learning. There were three occupational groups among doctors: surgeons $(n=47)$, therapists $(n=53)$ and pediatricians $(\mathrm{n}=48)$.

In the work a range of methods are used: content analysis, biblio-semantic, systematic approach, analysis of products of activity, psycho-diagnostic methods.

\section{RESULTS}

The term "competency approach in medical education" became widespread in the early 2000s. despite its widespread use, however, there are differences in the use of appropriate terminology and related concepts. In our work, we will provide a brief historical overview of the term, focusing on a clear definition and measurement of the competence approach.

During the 1950s, R. Taylor established that medical training content (content) was delivered more effectively if it focused on clinical effectiveness [1]. Based on the works of R. Taylor, they have developed a concise description of the competency approach in medical education, distinguishing it from a subject-oriented and integrated curriculum on the following points:

1) The training is organized on the basis of the functions necessary for medical practice in a specific, defined environment
2) Belief that all medical students can master at least the basic learning goals

3) The belief that learning and learning processes can be empirically researched and measured [2].

According to researchers [2], the expected result of a competent approach in medical training is a healthcare professional who can practice medical practice at a certain specific professional level, according to local conditions and needs. As a result-oriented competency approach in medical education, much attention is paid to postgraduate education and training.

The word "competence", most literally interpreted as "the ability or inability to do something successfully and / or effectively," has often led to confusion among teachers. As the competency approach in education did not always fit within this definition, the term "competence" was rethought.

The Council of Education of the Netherlands has proposed [3] a definition of competency that includes six attributes: competence is specific, complex, sustainable, performance-oriented, mastered, and competencies are mutually dependent. This coincides with the later definition of researchers [4] who added that competencies should reflect external expectations and lead to behaviors that would be measured using absolute standards, that is, completely independent of the results and behavior of other students. Other authors have emphasized [5] that the ability to act successfully is to some extent dependent on the context of circumstances and events. A person may have competence in one context, for example, on a beautiful clear day in a well-equipped hospital, but may not have competence in another setting, such as during a nighttime rainstorm in a remote countryside in the complete absence of medication and equipment.

If we call the ability to work effectively in the entirety of the medical profession "Medical competence," then med- 
Table II.Percentages of integral indicators by the method of diagnostics of social and psychological adaptation of Rogers - Diamond

\begin{tabular}{|c|c|c|c|c|c|}
\hline № & Integrated Indicators & $\begin{array}{c}\text { Surgeons } \\
(n=47)\end{array}$ & $\begin{array}{l}\text { Therapists } \\
(n=53)\end{array}$ & $\begin{array}{l}\text { Pediatricians } \\
\quad(n=48)\end{array}$ & $\begin{array}{l}\text { Overall } \\
(n=148)\end{array}$ \\
\hline 1. & Adaptation & 71 & 78 & 75 & 75 \\
\hline 2. & Acceptance of others & 74 & 81 & 78 & 78 \\
\hline 3. & Internship & 63 & 72 & 68 & 68 \\
\hline 4. & Self-perception & 60 & 69 & 65 & 65 \\
\hline 5. & Emotional comfort & 71 & 78 & 75 & 75 \\
\hline 6. & Striving for domination & 83 & 88 & 85 & 85 \\
\hline
\end{tabular}

Table III. Arithmetic mean values by the method of investigation of the motivation of Shane's professional career.

\begin{tabular}{|c|c|c|c|c|c|}
\hline № & Scales & $\begin{array}{c}\text { Surgeons } \\
(n=47)\end{array}$ & $\begin{array}{c}\text { Therapists } \\
(n=53)\end{array}$ & $\begin{array}{l}\text { Pediatricians } \\
\quad(n=48)\end{array}$ & $\begin{array}{l}\text { Overall } \\
(n=148)\end{array}$ \\
\hline 1. & Professional competence & 42,1 & 34,6 & 36,3 & 37,7 \\
\hline 2. & Management & 33,4 & 36,5 & 28,2 & 32,7 \\
\hline 3. & Autonomy & 29,3 & 28,3 & 24,5 & 27,4 \\
\hline 4. & Stability (places of work and residence) & 19,4 & 32,7 & 34,6 & 28,9 \\
\hline 5. & Service & 34,3 & 41,9 & 38,7 & 38,3 \\
\hline 6. & Challenge & 43,7 & 32,5 & 34,4 & 36,9 \\
\hline 7. & Lifestyle integration & 28,6 & 39,7 & 41,6 & 36,6 \\
\hline 8. & Entrepreneurship & 21,7 & 28,4 & 25,8 & 25,3 \\
\hline
\end{tabular}

ical competence can be defined as a mastered, sustained, and measurable ability to perform a specific complex task that is part of the whole set of tasks that make up the medical profession as a whole. This is a generalized ability, the specific manifestations of which can vary greatly depending on the situational context. As defined by R. Epstein and E. Gundert [5], areas of competence are higher-level entities that encompass several competence units. For example, patient care will include competencies such as "ability to collect patient information", "accurate medical examination" and "develop and implement a management plan".

The following psycho-diagnostic techniques were used for the experimental study:

1) The method of diagnostics of social and psychological adaptation of Rogers - Diamond;

2) A technique for researching the motivation of Shane's professional career;

3) Questionnaire "Style of self-regulation of behavior";

4) Questionnaire on implicit theories and learning goals K. Dwek.

According to the method of diagnostics of social and psychological adaptation of Rogers - Diamond, we surveyed our sample of 148 physicians who began the study of the discipline "Psychology of conflict", which was specially developed by us on the principles of adaptive learning.

There were three occupational groups among doctors: surgeons $(n=47)$, therapists $(n=53)$ and pediatricians $(\mathrm{n}=48)$. The results by the method are shown in table. I. and table. II.

The results obtained can be interpreted as follows. In general, the sample was diagnosed with low falsehood, which means that the subjects were sincere in their answers (arithmetic mean 3 at norms from 18 to 36 ). Only on two scales - "Disadaptability" and "Non-acceptance" - the arithmetic mean went beyond the normative values, in particular in these cases were lower. This indicates the overall sufficiently high adaptability of the sample under study, as well as the tendency to accept oneself as they are.

If we analyze the results by groups of doctors (surgeons, therapists, pediatricians), we see the following picture. The least adapted surgeons (108), the most therapists (121). The value of pediatric adaptability is in line with the overall mean of the sample (115).

Surgeons (43) are more likely to accept themselves as they are, while therapists (28) are less likely too.

Pediatricians have the highest scores on acceptance by others (25), while surgeons have the lowest (14).

Therapists have the highest rates of emotional comfort (29), while surgeons have the lowest scores again on this scale (17).

Surgeons are most prone to internal control (48), while pediatricians are most important to external control (22).

Surgeons are most likely to be dominant (14), while pediatricians are least likely to be (8).

Therapists are more inclined to escapism (escape from problems) than representatives of other medical specialties (16), while for surgeons' escapism is the least characteristic (8).

If to characterize the revealed and calculated integral indicators, the most pronounced for the whole study sample is the desire for dominance $(85 \%)$, adaptation and emotional comfort at the level of $75 \%$, the lowest percentage of the total. adoption - $65 \%$, slightly higher internality (68\%). Acceptance of others at $78 \%$. 
Table IV. Arithmetic mean values of the Behavior Self-Regulation Questionnaire

\begin{tabular}{|c|c|c|c|c|c|}
\hline № & Regulatory Scales & $\begin{array}{c}\text { Surgeons } \\
(n=47)\end{array}$ & $\begin{array}{l}\text { Therapists } \\
(n=53)\end{array}$ & $\begin{array}{l}\text { Pediatricians } \\
\quad(n=48)\end{array}$ & $\begin{array}{l}\text { Overall } \\
(n=148)\end{array}$ \\
\hline 1. & Overall level of self-regulation & 33,8 & 32,9 & 30,1 & 32,3 \\
\hline 2. & Planning (PI) & 5,3 & 7,1 & 6,2 & 6,2 \\
\hline 3. & Modeling (M) & 7,1 & 5,3 & 4,8 & 5,7 \\
\hline 4. & Programming (PR) & 6,2 & 4,8 & 3,6 & 4,9 \\
\hline 5. & Score of results (SR) & 5,7 & 6,5 & 6,7 & 6,3 \\
\hline 6. & Flexibility (F) & 4,3 & 6,3 & 5,2 & 5,3 \\
\hline 7. & Independence (I) & 7,2 & 5,6 & 6,1 & 6,3 \\
\hline
\end{tabular}

In interpreting the data as a whole, it should be noted that, as a whole, the three study groups have adapted and ready for adaptive learning in the postgraduate medical education system.

However, some psychological peculiarities of adaptation of the studied groups revealed the necessity of individual approach and development of informational and psychological recommendations of adaptive training of doctors, which would be based on the data of psycho-diagnostic examination.

The results of the psycho-diagnostic experiment by the method of investigation of the motivation of Shane's professional career are presented in Table. III.

In interpreting the results of a psycho-diagnostic study by the method of examining the motivation of Shane's professional career, the following should be noted. Different profiles of professional motives and values have been identified for surgeons, therapists and pediatricians.

Surgeons (47) are most challenge oriented (43.7) and professional (42.1). This means that their core values are competition, overcoming obstacles and solving complex problems. The social situation can be perceived by such professionals in the win-lose dichotomy. In their professional activities, novelty, diversity and challenge are important to these people. At the same time, the value of professional competence indicates that the surgeons under study have the capabilities and talents in their professional field. They want to be masters of their business. They are particularly pleased with their success in their work. Such people can quickly lose interest in a job that does not allow them to develop their own abilities and talents. At the same time, recognition and a certain social status are important.

Therapists (53) are most ministry oriented (41.9). This means that the main values for them are "service to humanity", "desire to make the world a better place", "help to others" and so on. This orientation is very favorable in a person-to-person ergodic system, because the therapists we studied are primarily focused on the benefit of other people.

Pediatricians (48) have the most pronounced professional motivation for integrating lifestyles (41.6). This means that these professionals are focused on the unity and balance of different aspects of their lives. They do not want family, career or personal development to dominate - the main thing is that everything is in harmony. Such profes- sionals value their lives more generally than a particular job or career.

The results of the psycho-diagnostic experiment by the method "Style of self-regulation of behavior" are given in Table. IV.

Surgeons have the highest overall level of self-regulation (33.8), according to the normative data such indicators refer to a high level of self-regulation. The lowest overall level of self-regulation in the sample has pediatricians $(30,1)$, according to the normative data, these indicators refer to the average level of self-regulation. Therapists have an indicator of 32.9, which according to the normative data refers to the average level of self-regulation.

According to the "Planning (PL)" scale, the therapists have the highest rates. This scale refers to the individual self-regulatory characteristics of goal setting and the ability to reach the goal, as well as the formation of informed planning of activities.

The therapists our study shows have high scores on this scale, which testifies to the realistic detail, hierarchy and constancy of the plans, as well as independence in the pursuit of the goals of the activity.

The lowest arithmetic scores on this scale in surgeons $(5,3)$, which, however, lie in the space of averages and can characterize both the surgeons we study and pediatricians $(6,2)$ as quite prone to scheduling.

On the scale of "Modeling $(\mathrm{M})$ " the highest rates at surgeons $(7,1)$, and by normative values these indicators can be characterized as high. This indicates that the surgeons we study have an individual development of ideas about internal and external meaningful conditions, their degree of awareness, adequacy and detail. Surgeons studied by us are able to identify significant conditions for achieving the goal in the present as well as in the future, which is manifested in the conformity of professional actions to the plans of activity and compliance of the obtained results with the stated goals. The lowest arithmetic scores on the Modeling (M) scale in pediatricians $(4,8)$, which, however, lie in the space of averages and can characterize both our pediatricians and therapists $(5,3)$ as being very prone to modeling their own activities and detail the conditions and circumstances that can lead to meaningful goals.

On the "Programming (Pr)" scale, the highest rates for surgeons (6.2). However, these indicators lie within the 
Table V. Arithmetic mean values by questionnaire of implicit theories and learning goals K. Dweck

\begin{tabular}{|c|c|c|c|c|c|}
\hline № & Scales & $\begin{array}{c}\text { Surgeons } \\
(n=47)\end{array}$ & $\begin{array}{l}\text { Therapists } \\
(n=53)\end{array}$ & $\begin{array}{l}\text { Pediatricians } \\
\quad(n=48)\end{array}$ & $\begin{array}{l}\text { Overall } \\
(n=148)\end{array}$ \\
\hline 1. & Adoption of the implicit theory of «increasing» intelligence & 7,1 & 6,5 & 8,1 & 7,2 \\
\hline 2. & Adoption of the implicit theory of «enriched» personality & 4,5 & 5,2 & 4,3 & 4,7 \\
\hline 3. & Acceptance of learning goals & 5,3 & 4,8 & 5,2 & 5,1 \\
\hline 4. & Self-esteem of the study & 4,2 & 3,9 & 4,8 & 4,3 \\
\hline
\end{tabular}

normative values of the average level of programming ability development. The therapists studied by us also have averages on this scale $(4,8)$. And pediatricians have low rates (3.6). This indicates a general tendency of inability and unwillingness to think through the sequence of their actions. Low Programming (PR) scores are also indicative of an inability to form an agenda of action, a propensity to act through trial and error. Surgeons and therapists, on the other hand, are more inclined to consciously program their own actions.

On the scale of "Score of results" (SR), the highest scores are found in pediatricians (6.7). However, these indicators, like those of therapists (6.5) and surgeons (5.7), relate to the average level of development of the adequacy of self-assessment and the results of one's own behavior and professional activity.

On the "Flexibility (F)" scale, the highest rates are found in therapists (6.3), the lowest in surgeons (4.3), and in pediatricians, the arithmetic mean is 5.2. By normative values, all of these indicators are considered to be of medium level of regulatory flexibility, that is, the ability to readjust and adjust to the system of self-regulation according to changes in external or internal conditions. This means that all the doctors we study are characterized by an average level of plasticity in regulatory processes.

On the scale of "Independence (I)", the highest rates are found in surgeons (7.2), the lowest in Therapists (5.6), and in pediatricians the arithmetic mean is 6.1. On this scale, the results of all three groups belong to the average level of development of regulatory autonomy.

This characterizes the moderate level of development of the ability to independently plan activities and behavior, to organize work to achieve this goal, to control the progress of work, to evaluate the intermediate and final results of the activity, in particular professional (in the medical field).

The results of the method of "Self-regulation style of behavior" by the doctors of the three medical specialties studied testify to their readiness for active inclusion in the system of adaptive training in postgraduate medical education.

The results of the psycho-diagnostic experiment according to the questionnaire of implicit theories and learning goals of K. Dweck are given in Table V.

Interpreting the results of the methodology, it should be noted that on the scale "Adopting the implicit theory of" incremental "intelligence" the highest results in pediatricians (8.1), the average of the study sample in surgeons (7.1), the lowest in therapists (6.5). This means that pediatricians are somewhat more likely to have implicit perceptions that intellectual capacity is developing and growing, especially if one is in an enriched environment. It should also be noted that pediatricians are dealing with children and can clearly see the results of intellectual development, sometimes quite significant, over time.

Representatives of all three study groups of physicians, to a lesser extent, tend to believe that personality changes under the influence of circumstances and interaction with other people. The highest scores on the scale "Acceptance of the implicit theory of" enriched "personality" in therapists $(5,2)$, lowest in pediatricians $(4,3)$, average in surgeons $(4,5)$. However, the difference between arithmetic averages is not significant. In general, our physicians are inclined to believe that personality enriches and develops in relationships with others, but these are moderate beliefs that relate less to ideas about personality development than to life-long intelligence. However, indicators on both scales suggest that there are implicit perceptions of "enriched" personality and "building up" intelligence, which is a good positive predictor of academic success and persistence. As with the previous methods, the results of the questionnaire of implicit theories and learning goals of K. Dweck testify to the readiness of our investigated physicians to adaptive learning in the system of postgraduate medical education.

The arithmetic mean across the sample of doctors on the Acceptance of Learning Goals scale is 5.1, with surgeons having the highest scores on this scale (5.3), while pediatricians average $(5.2)$ and therapists lowest $(4,8)$. On the Self-Assessment of Learning scale, pediatricians have the highest values (4.8), the lowest in therapists (3.9), and among them are the values obtained in the sample of surgeons (4.2). This means that the sample we study sufficiently accepts the goals of the training, sufficiently positively assesses their own learning and is ready for the experimental education system in the form of adaptive physician training.

\section{DISCUSSION}

In interpreting the data in general, it should be noted that, as a whole, the three study groups are adapted and ready for adaptive education in the postgraduate medical education system. However, some psychological peculiarities of adaptation of the studied groups revealed the necessity of individual approach and development of informational and psychological recommendations of adaptive training of doctors, based on the data of psycho-diagnostic exam- 
ination. Based on the above review, the implementation of the need for expert research on the effectiveness of the introduction of information and psychological component in the adaptive training of healthcare professionals motivates human behavior aimed at research and analysis new situations in the environment that arise with the emergence of new subjects and based on an emotional assessment of their relationships with other people, as well as their correlation with common values. It is argued that psychological adaptation is a process of motivating adaptive human behavior, the formation of goals and programs for its implementation, arising in response to the significant novelty of changes in the environment [1].

Significant changes in the thinking of higher education seekers cause the need for appropriate changes in their preparation for future professional activities. This is emphasized in the works of many researchers $[2,3,5]$. The outlined problem of using information and psychological components in adaptive education in the training of doctors in postgraduate education still remains unfinished. One of the ways to solve it can be the transition from traditional-subject to adaptive learning of such students. Therefore, it is necessary to select the leading principles of adaptive learning in order to implement them in the professional training of students in this field.

\section{CONCLUSIONS}

Our study groups are adapted and ready for adaptive education in the postgraduate medical education system. However, some psychological peculiarities of adaptation of the studied groups revealed the necessity of individual approach and development of informational and psychological recommendations of adaptive training of doctors, which would be based on the data of psycho-diagnostic examination.

The prospect of further research is related to the development of recommendations for adaptive physician training, based on a competency-based approach.

\section{REFERENCES}

1. Thayer McGahee, Maureen Bravo, Lisa Simmons, Tom ReidNursing Students and Service Learning: Research From a Symbiotic Community Partnership With Local Schools and Special Olympics. Nurse Educ. Jul/ Aug 2018;43(4):215-218.

2. Mulder M. Competence: the essence and use of the concept in ICVT. European Journal of Vocational Training. 2007; 40:5-21.

3. De Bruijn E. Authentic and self-directed learning in vocational education: challenges to vocational educators. Teaching and Teacher Education, 2011; 27: 694-702.

4. Taconis R. The development of professional competencies by educational assistants in school-based teacher education. European Journal of Teacher Education, 2004; 27: 215-240.

5. Epstein R. Defining and assessing professional competence. JAMA. 2002; 287(2): $226-235$.

This study was conducted within scientific and research (initiative-search) work of Shupyk National Medical Academy of Postgraduate Education entitled "Substantiation of innovative management models and optimization of organizational forms of activity of bodies, enterprises and health care institutions" (2020-2024, № state registration 01200U101680).

\section{ORCID and contributionship:}

Svitlana P. Koshova:0000-0002-7637-4311 D, E

Zoriana V. Hbur: 0000-0003-4536-2438 ${ }^{A, F}$

Andrii V. Kolomoyets: 0000-0002-1205-9419 ${ }^{B}$

\section{Conflict of interest:}

The Authors declare no conflict of interest.

\section{CORRESPONDING AUTHOR Svitlana P. Koshova}

Shupyk national medical academy of postgraduate education 9 Dorohozhytska Str., 04112 Kyiv, Ukraine

tel: +380636044333

e-mail.uoznmapo@ukr.net

Received:04.10.2020

Accepted: 01.03.2021

A - Work concept and design, B - Data collection and analysis, C - Responsibility for statistical analysis,

D-Writing the article, $\mathbf{E}$-Critical review, $\mathbf{F}$ - Final approval of the article 